\title{
Iodination of Aniline Using Thallium(III)-trifluoroacetate and Potassium Iodide
}

\author{
Siegmund L. Braun, Edith Dürmeyer, Karl Jacob and Wolfgang Vogt \\ Institut für Klinische Chemie, Klinikum Großhadern der Universität München, \\ Marchioninistraße 15, D-8000 München 70
}

Z. Naturforsch. 38b, 696-697 (1983); received February 2, 1983

Iodination, Aniline, $p$-Iodo-aniline, Thallium(III)-trifluoroacetate

A new procedure for a specific micro-synthesis of $p$-iodo-aniline has been developed. It consists of the reaction of aniline with thallium(III)-trifluoroacetate followed by the iodination with aqueous potassium iodide.

Electrophilic aromatic thallation followed by addition of aqueous potassium iodide is a simple and effective way to synthesize aromatic iodo compounds $[1,2]$. Although this procedure is applicable to a wide range of aromatic compounds, the reaction of aromatic amines with thallium(III)-trifluoroacetate has not been described. With unprotected amino groups a priori one would consider this reaction unlikely because of a possible oxidation by the thallium(III)salt or a complex formation leading to full inertness [3]. Nevertheless, we succeeded in preparing $p$-iodo-aniline from aniline via the direct thallation reaction without any protection of the amino group. The method presented here will be used further for a highly specific micro-synthesis of radioactively labelled $\mathrm{p}^{-125 I-a n i l i n e,}$ where we will work only with minute amounts of tracer.

Under the conditions described we obtained nearly exclusively $p$-iodo-aniline (see Fig. 1). $o$-Iodoaniline and higher iodinated anilines like di-iodoaniline were formed only in trace amounts $(<1 \%)$. $m$-Iodo-aniline could not be detected. Only $5 \%$ of the aniline remained unreacted, the yield of $p$-iodoaniline was $\mathbf{9 2 - 9 4 \%}$.

The simple procedure of thallation as described with 2 to $10 \mathrm{~min}$ incubation at room temperature gave the best results. A prolonged incubation time up to $24 \mathrm{~h}$ did not improve the thallation process. However, the reaction is highly influenced by temperature. Thallation between $0{ }^{\circ} \mathrm{C}$ and $10{ }^{\circ} \mathrm{C}$ reduces the yield of $p$-iodo-aniline drastically, most of the aniline remaining unreacted. At a thallation temperature of $50^{\circ} \mathrm{C}$ oxidation reactions are strongly

\footnotetext{
* Sonderdruckanforderungen an Dr. S. Braun. 0340-5087/83/0600-0696/\$01.00/0
}

enhanced, resulting in the formation of azobenzene and a variety of unidentified compounds.

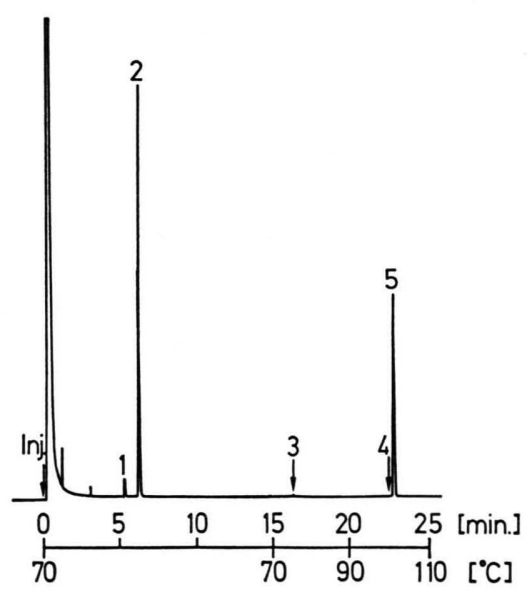

Fig. 1. Gas chromatographic analysis of a typical preparation of $p$-iodo-aniline.

Peaks: 1 aniline, 2 o-toluidine (internal standard), $3 o$-iodo-aniline, $4 \mathrm{~m}$-iodo-aniline, $5 \mathrm{p}$-iodo-aniline. Gas chromatographic conditions: $25 \mathrm{~m}$ SP-1000 glass capillary column, carrier gas $\mathrm{N}_{2}(3 \mathrm{ml} / \mathrm{min})$.

Thus we conclude that the direct thallation of aromatic amines can be specifically performed without side-reactions, provided that appropriate reaction conditions are applied.

\section{Experimental}

All thallation experiments were carried out in an atmosphere of dried argon. Gas chromatographic analyses were obtained with a model 1445 gas chromatograph (Varian) equipped with a $25 \mathrm{~m}$ SP-1000 glass capillary column. Injector $110^{\circ} \mathrm{C}$; column oven isothermal at $70^{\circ} \mathrm{C}$ for $15 \mathrm{~min}$, temperature program $70-140{ }^{\circ} \mathrm{C}$ with a heating rate of $4{ }^{\circ} \mathrm{C} / \mathrm{min}$; carrier gas $\mathrm{N}_{2} 3 \mathrm{ml} / \mathrm{min}$; split ratio $1: 10$; 
detector $240^{\circ} \mathrm{C}$ (flame ionization detector). Combined gas chromatography - mass spectrometry was performed with a model MAT 311-A double focusing mass spectrometer (Finnigan-MAT) coupled with a model 1445 gas chromatograph, which was fitted to the ion source of the mass spectrometer with an all-glas open split-type connection. Gas chromatographic conditions were as described above with the exception of $\mathrm{He}$ as the carrier gas.

\section{p-Iodo-aniline}

$17 \mathrm{mg}(0.18 \mathrm{mmol})$ aniline in $0.4 \mathrm{ml}$ purified and anhydrous acetonitrile were mixed with $97.8 \mathrm{mg}$ $(0.18 \mathrm{mmol})$ thallium(III)-trifluoroacetate, dissolved in $0.4 \mathrm{ml}$ acetonitrile, and $0.05 \mathrm{ml}$ trifluoroacetic acid. The reaction mixture was stirred for 2 to $10 \mathrm{~min}$ at room temperature $\left(20\right.$ to $\left.25^{\circ} \mathrm{C}\right)$.
According to the procedure of McKillop et al. [1] thallation was followed by the stepwise addition of $29.9 \mathrm{mg}(0.18 \mathrm{mmol})$ potassium iodide in $1 \mathrm{ml}$ water and $17.1 \mathrm{mg}(0.09 \mathrm{mmol})$ sodium metabisulfite. The solution was brought to $\mathrm{pH} 11$ with $0.2 \mathrm{ml}$ $5 \mathrm{~mol} / \mathrm{l}$ sodium hydroxide. $p$-Iodo-aniline (yield 92 to $94 \%$ ) was extracted with three $1 \mathrm{ml}$ portions of diethylether. Positive identification of the reaction product was by combined gas chromatography - mass spectrometry comparing both the retention time and the mass spectrum with those of an authentic sample. The yield was determined by gas chromatography using $o$-toluidine as the internal standard, which was added prior to the extraction step.

We are indebted to Mrs. R. Kubbe and Mrs. G. Schwertfeger for their skilful technical assistance.
[1] A. McKillop, J. S. Fowler, M. J. Zelesko, and J. D. Hunt, Tetrahedron Lett. 1969, 2427.

[2] A. McKillop, J. D. Hunt, M. J. Zelesko, J. S.
Fowler, E. C. Taylor, G. McGillivray, and F. Kienzle, J. Am. Chem. Soc. 93, 4841 (1971).

[3] A. McKillop, personal communication. 